\title{
A common factor in hypertrophic osteoarthropathy
}

\author{
K. B. C A R R O L L a n d L. D O Y L E
}

Cardiothoracic Department, Wythenshawe Hospital, Manchester

\begin{abstract}
Carroll, K. B. and Doyle, L. (1974). Thorax, 29, 262-264. A common factor in hypertrophic osteoarthropathy. Two cases of oesophageal disease with hypertrophic osteoarthropathy are presented. The unusual site of the primary lesion has prompted a review of the literature and led to the conclusion that there is a common innervation accounting for a common afferent arc which is an integral and basic part of the mechanism in this disorder.
\end{abstract}

The pathogenesis of hypertrophic osteoarthropathy (HO) remains an enigma. It may be associated with disease in a variety of organs and in a wide range of pathological conditions in those organs. We present two unusual and rare causes of $\mathrm{HO}$ and propose a common factor in all cases of $\mathrm{HO}$.

\section{CASE REPORTS}

PATIENT J. M. A 78-year-old woman presented in 1959 with a three-month history of increasing dysphagia. For four to five months before admission she had noted swelling and stiffness in both ankles and wrists. Pitting oedema was easily demonstrable on the dorsum of the feet, ankles, and lower part of the legs and on the dorsum of the hands. Radiographs showed well-marked periosteal new bone formation on the tibiae, fibulae (Fig. 1), radii, and ulnae. Chest films and bronchoscopy were normal; in particular there was no evidence of bronchial carcinoma. Oesophagoscopy and biopsy revealed an adenocarcinoma in the middle third of the oesophagus. In view of the patient's age and frailty no operative intervention was undertaken and she died shortly after.

PATIENT S. L. A 51-year-old man presented with a 10-year history of heartburn, especially at night; vomiting, occasionally with blood, was noted several times. From 1969 he had had aerophagy and slight dysphagia referred to the lower half of the sternum. From 1968 he had swollen and stiff ankles, stiff knees and wrists, and marked finger and toe clubbing.

The chest film appearances were normal, but radiographs of the femora, tibiae, fibulae, and radii (Fig. 2) showed marked periosteal new bone formation. A

'Present address: Cardiothoracic Institute, Brompton Hospital, London SW3 barium swallow showed the presence of a sliding hiatus hernia. Oesophagoscopy revealed the presence of severe confluent, ulcerative oesophagitis from the cardia to the level of the aortic arch.

Repair of the hiatus hernia was carried out in

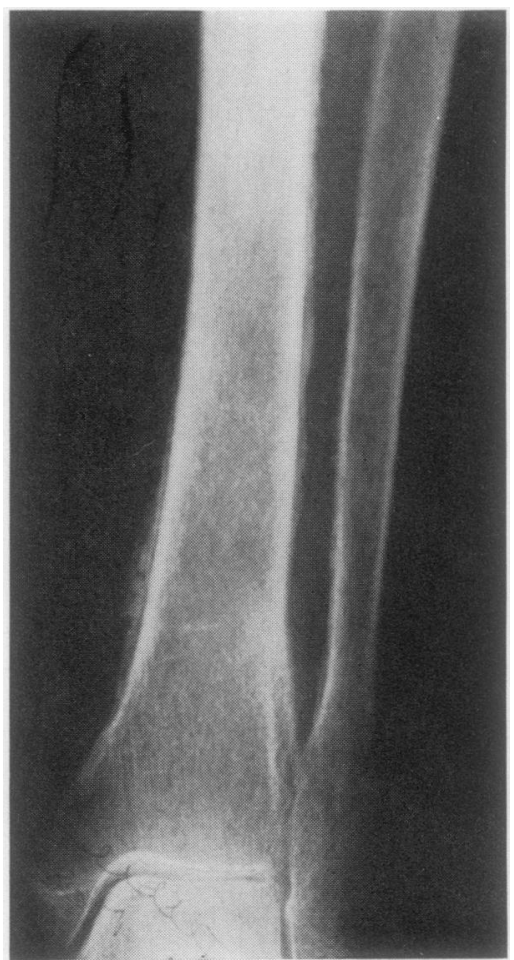

FIG. 1. Patient J. M. Tibia and fibula showing periosteal new bone formation. 


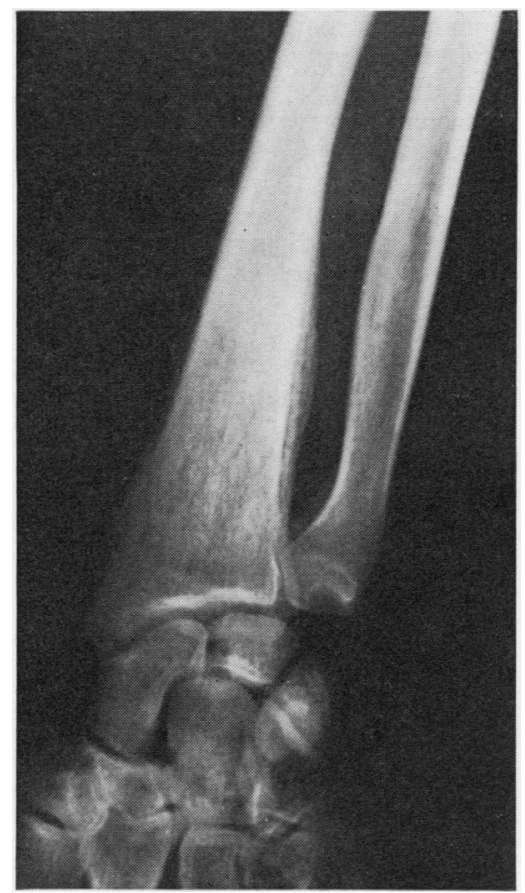

FIG. 2. Patient S.L. Well-marked periosteal new bone formation on left radius and ulna.

August 1971. Dramatic relief of symptoms of $\mathrm{HO}$ followed the operation. He remains well to date without any evidence of further intrathoracic or extrathoracic disease.

\section{DISCUSSION}

The vast majority of patients reported with HO are associated with an underlying pulmonary or pleural disease, usually cancer, bronchiectasis, or empyema. Oesophageal disease has been reported infrequently as a cause. Myomata (Joplin and Fraser, 1965), carcinoma (Maurice-Williams and Wilson, 1969; Coury, 1962), achalasia with carcinoma (Peyman, 1959), and achalasia without carcinoma (Naish, 1959) have been reported. Other gastrointestinal lesions associated with $\mathrm{HO}$ include nasopharyngeal carcinoma (Josserand, Pichat, and Chapuis, 1953), stomach cancer (Singh, Jolly, and Bansal, 1960), stomach diverticulum (Turiaf, Battesti, and Hardouin, 1966), hepatic cirrhosis (Buchan and Mitchell, 1967), and sprue (Hammersten and O'Leary, 1957). There appears to be no uniformity in primary pathology.

In cases associated with lung cancer Flavell (1956) noted reversal of HO by vagotomy, and this has been corroborated in dogs by Holling, Brodey, and Bowland (1961).

The viscera in which the primary disease is located have one thing in common: they are supplied by either the 9th or 10th cranial nerves. Mitchell (1956) pointed out that the 'vascular fibres of the glossopharyngeal nerves are distributed in their meningeal, tympanic, pharyngeal, tonsillar, lingual and carotid branches ... and the vagi supply cardiac, recurrent laryngeal, tracheal, oesophageal, gastric, pyloric, hepatic and coeliac branches and all are believed to carry a quota of fibres concerned with vascular innervation'. The afferent splanchnic fibres of both the 9th and 10th cranial nerves terminate in grey matter closely related to the dorsal nucleus (efferent) to the 9th and 10th nerves (Cunningham's Textbook of Anatomy, 1951). Thus, in $\mathrm{HO}$ the organs in which the causative disease is sited have a common feature-part of their afferent innervations (including part of their vascular afferent innervation) have a common nucleus of termination. We suggest that this might account for a common afferent arc as an integral and basic part of the mechanism responsible for $\mathrm{HO}$.

We wish to thank Mr. John Dark and Mr. Gordon Jack for allowing us to publish these case reports.

\section{REFERENCES}

Buchan, D. J. and Mitchell, D. M. (1967). Hypertrophic osteoarthropathy in portal cirrhosis. Annals of Internal Medicine, 66, 130.

Coury, M. (1962). Ostéoarthropathie hypertrophiante pneumique et cancer de l'oesophage. Bulletins et Mémoires de la Société Médicale des Hôpitaux de Paris, 113, 335.

Cunningham's Textbook of Anatomy (1951). 9th ed., edited by J. C. Brash, p. 928. Oxford Medical Publications.

Flavell, G. (1956). Reversal of pulmonary hypertrophic osteoarthropathy by vagotomy. Lancet, 1, 260.

Hammersten, J. F. and O'Leary, J. (1957). The features and significance of hypertrophic osteoarthropathy. Archives of Internal Medicine, 99, 431.

Holling, H. E., Brodey, R. S., and Bowland, H. C. (1961). Pulmonary hypertrophic osteoarthropathy. Lancet, 2, 1269.

Joplin, G. F. and Fraser, T. R. (1965). Oesophageal polyp with hypertrophic osteoarthropathy. Proceedings of the Royal Society of Medicine, 58, 576.

Josserand, A., Pichat, P., and Chapuis, H. (1953). Contribution à la pathogénie de l'ostéopathie hypertrophiante pneumique de Pierre-Marie 
d'après l'evolution de deux epithéliomas extrapulmonaires traités par chémiothérapie palliative. Lyon Médical, 190, 30.

Maurice-Williams, R. S. and Wilson, R. J. (1969). Hypertrophic osteoarthropathy associated with carcinoma of the oesophagus. Postgraduate Medical Journal, 45, 743.

Mitchell, G. A. G. (1956). Cardiovascular Innervation, pp. 125 and 127. Livingstone, Edinburgh.

Naish, J. (1959). Achalasia of cardia and osteoarthropathy. British Medical Journal, 1, 365.

Peyman, M. A. (1959). Achalasia of the cardia, carcinoma of the oesophagus and hypertrophic pulmonary osteoarthropathy. British Medical Journal, 1, 23.

Singh, A., Jolly, S. S., and Bansal, B. B. (1960). Hypertrophic osteoarthropathy associated with carcinoma of the stomach. British Medical Journal, 2, 581.

Turiaf, J., Battesti, J. P., and Hardouin, J. P. (1966). Ostéoarthropathie hypertrophiante et diverticule de l'estomac. Poumon et le Coeur, 22, 605.

Requests for reprints to: Dr. K. B. Carroll, Cardiothoracic Institute, Brompton Hospital, London SW3. 